\title{
Design and Manufacture of Industrially Representative Weld Mock-ups for the Quantification of Residual Stresses in a Nuclear Pressure Vessel Steel
}

\author{
J. A. Francis ${ }^{1, a^{*}}$, M. C. Smith ${ }^{1, b}$, B. Jeyaganesh ${ }^{1,2, c}$, A. N. Vasileiou ${ }^{1, d}$ \\ D. W. Rathod ${ }^{1, \mathrm{e}}$, M. J. Roy ${ }^{1, \mathrm{f}}$ and N. M. Irvine ${ }^{3, \mathrm{~g}}$ \\ ${ }^{1}$ School of Mechanical, Aerospace and Civil Engineering, The University of Manchester, \\ Manchester M13 9PL, United Kingdom \\ ${ }^{2}$ Nuclear AMRC, University of Sheffield, Rotherham S60 5WG, United Kingdom \\ ${ }^{3}$ Dalton Nuclear Institute, The University of Manchester, Manchester M13 9PL, United Kingdom \\ ajohn.francis@manchester.ac.uk, 'bmike.c.smith@manchester.ac.uk, \\ jey.balakrishnan@namrc.co.uk, danastasia.vasileiou@manchester.ac.uk, \\ edinesh.rathod@manchester.ac.uk, ' ${ }^{\mathrm{f}}$ matthew.roy@manchester.ac.uk, \\ gneil.irvine@manchester.ac.uk
}

Keywords: Boundary Conditions, Distortion, Instrumentation, Laser Scanning, Narrow Groove Weld, Weld Design, Weld Restraint

\begin{abstract}
This paper describes work carried out under the NNUMAN research programme. This work focuses on the measurement and modelling of residual stresses in weld test pieces that have a thickness that is representative of primary components in a pressurised water reactor, such as the steam generators and the pressuriser. Weld test pieces at thicknesses of $30 \mathrm{~mm}$ and $130 \mathrm{~mm}$ have been and are being manufactured in SA508 Grade 3 Class 1 steel. Attention has been given to welding processes that are currently applied in nuclear manufacturing, such as narrow-groove arcbased welding processes, as well as to candidate processes for future build programmes, such as electron beam welding. The manufacture, characterisation and modelling of large test pieces each present challenges over and above those that arise when dealing with the smaller test pieces that are more typically manufactured in research laboratories. Some of those challenges, and the approaches that have been used to overcome them, are described. Plans for future work are briefly mentioned.
\end{abstract}

\section{Introduction}

Residual stresses can play a significant role in affecting the long-term structural performance of safety-critical components in nuclear power plants. Residual stresses can contribute to the driving force for crack growth [1] but, in nuclear environments, they can also activate degradation mechanisms such as creep [2] and stress-corrosion cracking [3] even in the absence of operating stresses. This is significant because many safety-critical components in a nuclear plant undergo welding during manufacture, and welding is known introduce substantial levels of residual stress [4].

The primary options for quantifying residual stresses in welds are to measure them, or to make predictions based on numerical models. However, both approaches are not straightforward since, on the one hand, many measurement techniques are either destructive or not suited to applications on large components and, on the other hand, numerical models must undergo rigorous validation before they can be used with confidence, through comparisons with measurements made with multiple and dissimilar techniques on test cases for which the manufacturing history has been documented in detail. This highlights the need for carefully designed weld mock-ups that can serve as weld modelling benchmarks. Such benchmarks enable weld models to be validated on well-defined test cases before they are applied to make predictions for real components. 
As part of the NNUMAN research programme, we have designed and are manufacturing weld mock-ups that are larger than those that are typically manufactured in a laboratory environment. In doing so, our aim is to gain a better appreciation of the manufacturing challenges that are encountered when large nuclear components are manufactured in practice. Our hope is that, by manufacturing weld mock-ups that are more representative of welds that are made on an industrial scale, we will use welding procedures that are closer to those applied in practice, we will capture a greater range of relevant phenomena, and we will thereby reduce the uncertainties associated with inferring trends for industrial scale welded joints based on extrapolation from laboratory scale test pieces. While the motivation is straightforward, the manufacture of these weld mock-ups has presented different challenges to those that we encounter when making smaller weld test pieces. Thus the purpose of this paper is to highlight some of these challenges and the approaches we are employing to meet them.

\section{Research Objectives}

Welding research under the NNUMAN programme has the overarching aim of developing an understanding of how the choice of manufacturing process impacts on the performance of reactor components over the design life of the component, which for new build applications is typically $60+$ years. This aim is quite distinct from the basic manufacturing requirement to produce a weld that will meet start-of-life weld quality requirements and pass inspection so that it will go into service. In this work, we have focused on welds made in SA508 Grade 3 Class 1 steel, which is a low-alloy steel that is typically used in the manufacture of primary components in a pressurised water reactor (PWR) such as the reactor pressure vessel or the steam generators. For this steel, and for such components, the parameters that will have the greatest influence of long-term structural integrity include the fracture toughness of the weld region and the weld residual stress distributions. Accordingly, the NNUMAN welding research programme has the following objectives:

- To manufacture industrially-representative weld mock-ups with welding processes that are currently applied to nuclear components, as well as with welding processes that may be used in future build programmes. The welding processes that have been chosen for investigation are narrow-groove gas-tungsten-arc welding (NG-GTAW), narrow-groove submerged arc welding (NG-SAW), electron beam (EB) welding and laser welding;

- To carefully record and document all aspects of the manufacturing processes and steps that are employed in each case so that the weld mock-ups can be used as the basis for validating numerical models for welding;

- To characterise the weld residual stress distributions in each of the weld mock-ups using multiple measurement techniques;

- To develop a methodology for the modelling of each weld and welding process so that residual stresses can be predicted and the interaction between the welding process and material can be understood.

\section{Design Requirements for Weld Mock-Ups}

The design requirements included (but were not limited to) the following:

- The thickness of the weld mock-ups should be representative of the thicknesses that are applicable to primary components in a PWR;

- The length and width of the weld mock-ups should be sufficient to enable steady-state welding conditions to be achieved along the length of the weld and for the residual stress distributions to be substantially unaffected by the width of the test pieces;

- The boundary conditions, particularly with respect to weld restraint, should be either clearly defined or well characterised.

In terms of the first requirement, a thickness of $130 \mathrm{~mm}$ was identified as being representative. The last requirement that is listed above is of great importance since welds usually need to be restrained in some way during manufacture in order to prevent excessive distortion. When this restraint is released, there will inevitably be some spring back and associated relaxation of residual stress. While 
this can (in principle) be accounted for, unfortunately, common methods of restraint (e.g. clamping and tack welding of test pieces to backing plates) tend to provide levels of restraint that are not easily quantified. This means that such approaches can be difficult to represent accurately in numerical models. In addition to manufacturing welds at a thickness of $130 \mathrm{~mm}$, it was decided that test pieces should also be manufactured at a thickness of $30 \mathrm{~mm}$, as such an exercise would serve as a stepping stone in terms of the development of welding procedures and associated weld models, and it would also enable residual stresses to be characterised with neutron diffraction (not feasible at a thickness of $130 \mathrm{~mm})$.

\section{Basic Geometry}

The basic geometries of the $30 \mathrm{~mm}$ and $130 \mathrm{~mm}$ thick specimens are shown in Figure 1 . The $30 \mathrm{~mm}$ thick arc- and laser-welds had a geometry that was similar to that shown in Figure 1 (left). It can be seen that these $30 \mathrm{~mm}$ thick welds are not full-length groove welds, and that a ligament of parent material remained intact at either end. These ligaments served to provide a degree of self-restraint, so that the specimens did not need to be clamped or restrained with any significant force. Instead, light clamping could be employed simply to prevent the specimens from moving during welding. Furthermore, the specimen geometry could be captured in finite-element models so that the extent of self-restraint could be represented accurately. For the electron beam weld, it was possible to leave the weld free of restraint, due to the process requiring only a single weld pass. For the $130 \mathrm{~mm}$ thick specimens, a self-restraining approach was not feasible, and another method of restraint was developed.
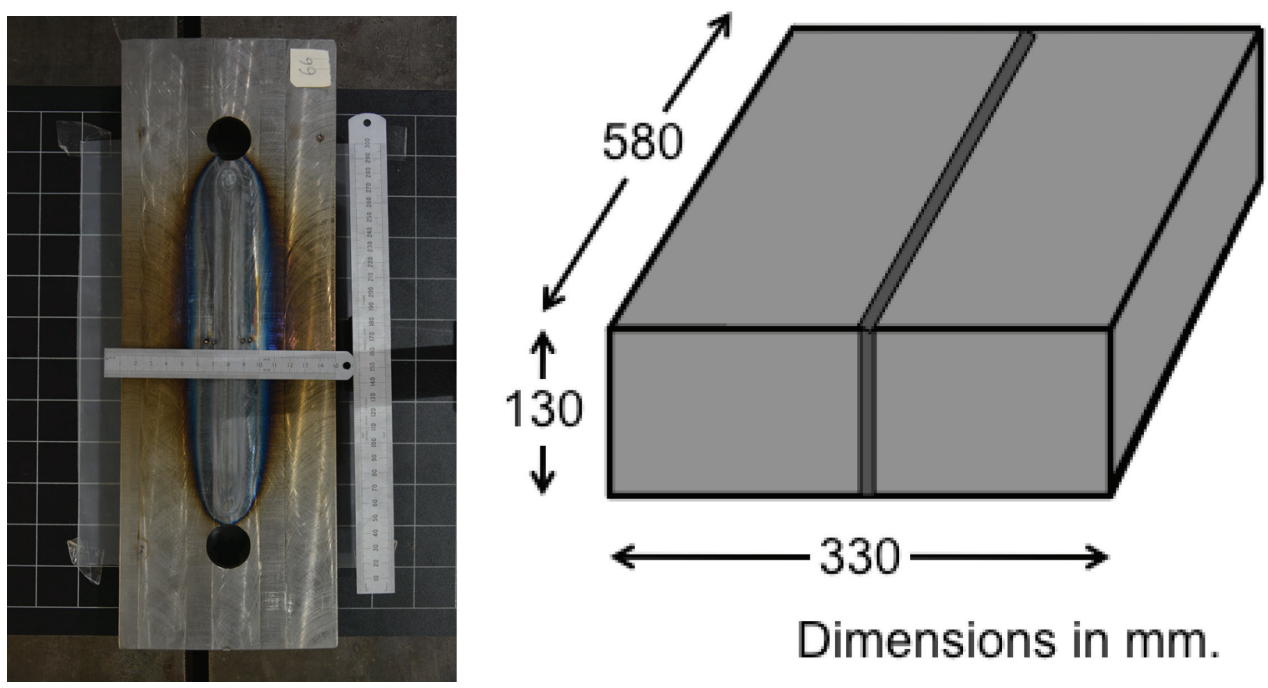

Fig. 1: Photograph of a $30 \mathrm{~mm}$ thick submerged arc welded specimen (left) showing ligaments of parent material that remain intact at each end of the specimen, and schematic representation of basic specimen geometry for the $130 \mathrm{~mm}$ thick weld mock-ups (right). The weld seam runs along the centre of the specimen in both cases.

\section{Challenges Associated with Distortion}

One of the major challenges in developing welding procedures for the $130 \mathrm{~mm}$ thick specimens was controlling the distortion of the welds, and designing weld grooves that would enable welds to be completed successfully in spite of this distortion. There are two components to this distortion, namely butterfly distortion, and transverse contraction, and both are represented schematically in Figure 2. Multipass welds made from one side experience both components of distortion. For these welds, butterfly distortion in particular can create problems with respect to the weld groove progressively closing as successive weld passes are deposited. If a narrow groove weld torch is used, then butterfly distortion can raise the possibility of the torch becoming trapped between the two 
plates being joined. In this work, a restraint rig (Fig, 3) was designed, built and commissioned to mitigate butterfly distortion in multipass welds. Butterfly distortion is minimal in single-pass electron beam welds, so no restraint was applied with this welding process.
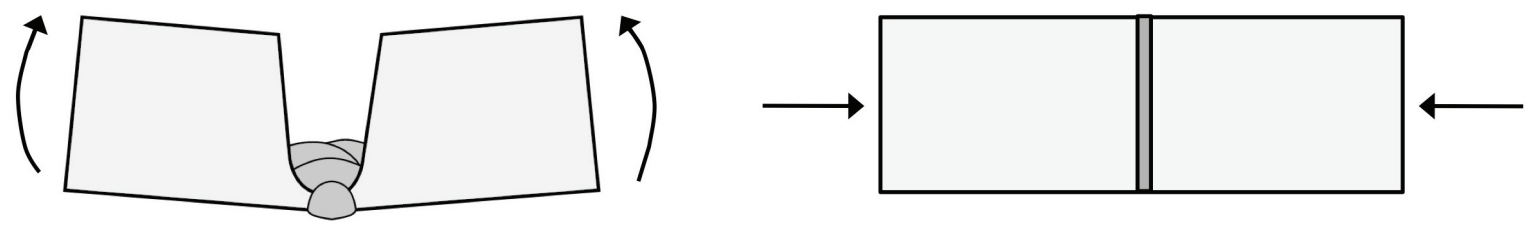

Fig. 2: Schematic representation of butterfly distortion (left), which is typically associated with one-sided multipass welds, and transverse contraction (right) as viewed on a cross-section through a single-pass electron beam weld. Transverse contraction occurs in all fusion welds to some degree. In both cases the welding direction runs into the page.

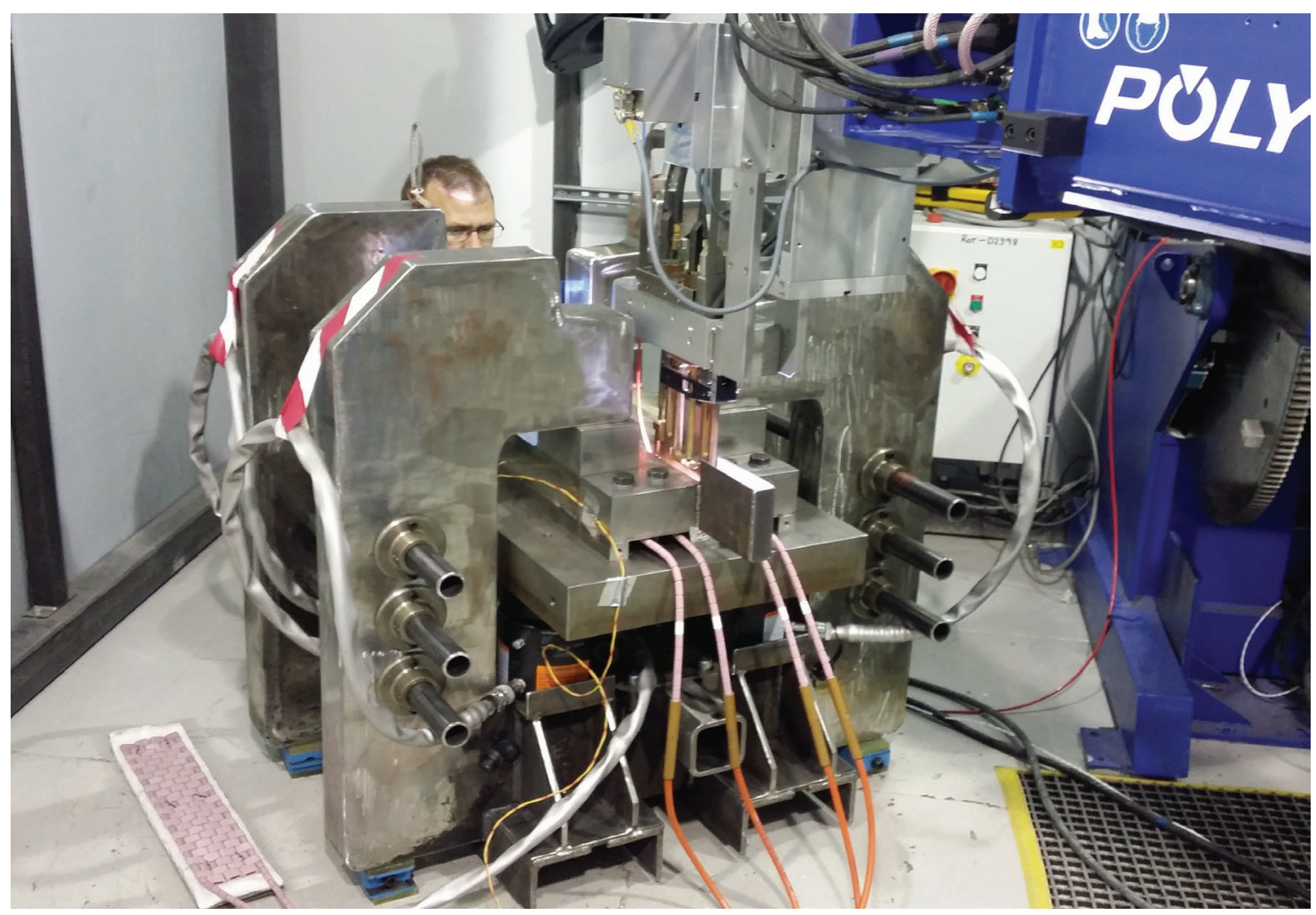

Fig. 3: Photograph of restraint rig that was designed, built and commissioned for the purpose of manufacturing the $130 \mathrm{~mm}$ thick weld mock-ups in the NNUMAN research programme. The weld assembly sits on a support plate which is pushed upwards so that the king plates apply restraint.

Although the restraint conditions differ for the multipass welds and the single pass welds, as well as for the $30 \mathrm{~mm}$ thick and $130 \mathrm{~mm}$ thick welds, this in itself does not create problems from the standpoint of directly comparing different welding processes. The most important requirement in the NNUMAN research programme is that the restraint conditions are understood and any restraint, if applied, can be quantified and represented in a finite-element model. In this respect, both the selfrestraining specimen configuration $(30 \mathrm{~mm})$ and the employment of a restraint rig $(130 \mathrm{~mm})$ meet these criteria. In cases where the restraint rig was employed, the loads that were applied have been logged by recording the pressure of the hydraulic oil being supplied to the actuators (these raise the support plate so that it pushes the specimen assembly against the king plates in order to apply the restraint). Strain gauges have also been attached to the main structure of the rig to record the strains that develop as welding progresses. The distortions that develop during welding have also been 
recorded before and after every weld pass in order to provide further information that may be of use in developing and assessing the performance of weld models. The distortions have been recorded with a 3-dimensional laser scanner, as well as by adding pockmarks to the specimens and manually measuring the movement of these marks between weld passes. Examples of the type of information that has been recorded are shown in Fig. 4.
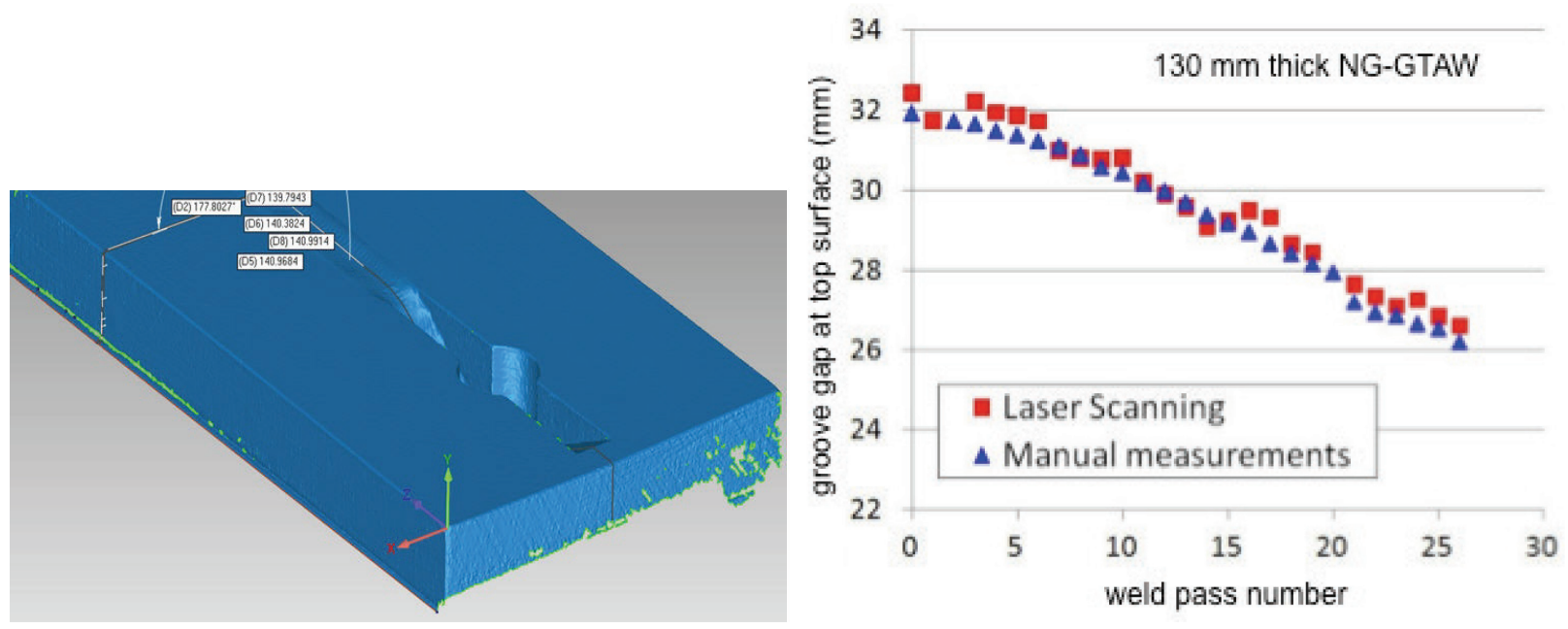

Fig. 4: An example of the three-dimensional information that was obtained from the hand-held laser scanner for a $30 \mathrm{~mm}$ thick weld test piece (left), and an illustration of the extent to which the groove gap at the top surface of a $130 \mathrm{~mm}$ thick GTAW specimen reduces as successive weld passes are deposited. Note that, with the welding parameters that were used for the GTAW specimen, approximately 80 weld passes are required to complete a $130 \mathrm{~mm}$ thick joint.

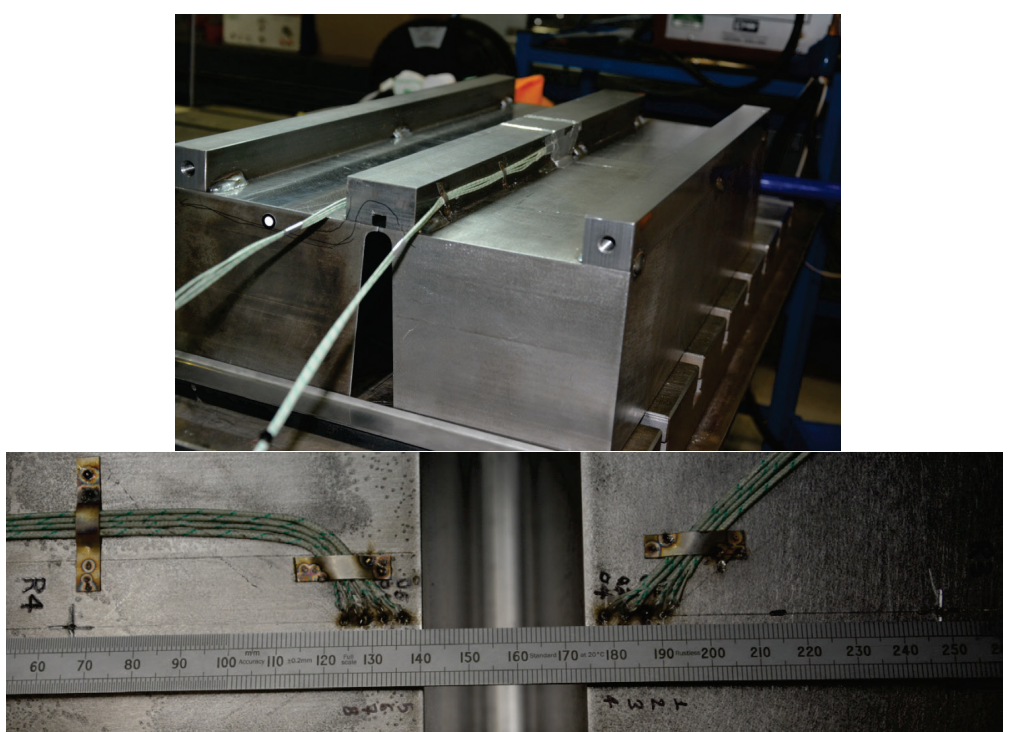

Fig. 5: Photograph of a $130 \mathrm{~mm}$ thick submerged arc weld specimen (left) placed up-side-down prior to the commencement of welding to reveal a backing channel, which allows an inert gas to shield the root of the weld bead from the atmosphere during welding, and which also provides access for thermocouples and preheating blankets at the base of the specimen. The thermocouples attached to the top surface of the weld are shown (right) prior to the commencement of welding. 


\section{Other Challenges}

Other challenges associated with the $130 \mathrm{~mm}$ thick specimens have included the need to attach thermocouples and strain gauges to the specimens (for the purpose of validating models), whilst providing access for shielding gas to both sides of the plate (to prevent weld contamination), as well as preheating blankets (to prevent hydrogen cracking), all while not interfering with the ability of the restraint rig to apply the restraining loads. Figure 5 shows the way in which access to the underside of the $130 \mathrm{~mm}$ thick specimens was provided for these concurrent requirements. Finally, it should be mentioned that the need to apply multiple residual stress measurement techniques to each weld mock-up will result in the $30 \mathrm{~mm}$ thick specimens being characterised with neutron diffraction and the contour method, while the $130 \mathrm{~mm}$ thick specimens will be characterised using the incremental deep hole drilling technique and the contour method.

\section{Summary}

Weld mock-ups of a thickness that is representative of primary nuclear components (i.e. $130 \mathrm{~mm}$ ) have been designed and are currently being manufactured in SA508 Grade 3, Class 1 steel. The purpose of these test pieces is to enable residual stresses to be evaluated and to enable a cross-process comparison to be made, which will involve both welding processes that are currently being applied on nuclear plants and candidate processes for future nuclear build programmes. A matching matrix of welds has also been manufactured at a thickness of $30 \mathrm{~mm}$, since this thickness is amenable to residual stress measurements using neutron diffraction. The thermal histories, restraint boundary conditions and the evolution of distortion during manufacture have been and are being recorded in detail. Residual stresses are being measured in each specimen using multiple techniques. These welds will provide what we believe to be the most comprehensive comparison of current and candidate welding processes for nuclear pressure vessels. The authors hope that these mock-ups will provide invaluable insights relating to the generation of weld residual stresses, and serve as modelling benchmarks for years to come.

\section{Acknowledgements}

The authors would like to acknowledge the Engineering and Physical Sciences Research Council (EPSRC) for supporting this work through the NNUMAN Research Programme (Grant No. EP/J021172/1), and Dr. Alan Thompson, formerly with Tata Steel Europe, for valuable discussions.

\section{References}

[1] P.J. Withers: Residual Stress and its Role in Failure. Reports on Progress in Physics, Vol. 70 (2007), pp. 2211-2264. https://doi.org/10.1088/0034-4885/70/12/R04

[2] M. Turski; P.J. Bouchard; A. Steuwer; P.J. Withers: Residual Stress Driven Creep Cracking in AISI Type 316 Stainless Steel. Acta Materialia, Vol. 56 (2008), pp. 3598-3612. https://doi.org/10.1016/j.actamat.2008.03.045

[3] D.J. Hornbach; P.S. Prevey: The Effect of Prior Cold Work on Tensile Residual Stress Development in Nuclear Weldments', Journal of Pressure Vessel Technology, Vol. 124 (2002), pp. 359-365. https://doi.org/10.1115/1.1481035

[4] J.A. Francis; H. K. D. H. Bhadeshia; P. J. Withers: Welding Residual Stresses in Ferritic Power Plant Steels. Materials Science and Technology, Vol. 23 (2007), No. 9, pp. 1007-1020 